\title{
Biliary drainage method and temporal trends in patients admitted with cholangitis: A national audit
}

\author{
Julia McNabb-Baltar MD FRCPC ${ }^{1}$, Quoc-Dien Trinh MD FRCSC ${ }^{2,3}$, \\ Alan N Barkun MD CM FRCPC FACP AGAF FACG MSc ${ }^{1}$
}

\begin{abstract}
J McNabb-Baltar, Q-D Trinh, AN Barkun. Biliary drainage method and temporal trends in patients admitted with cholangitis: A national audit. Can J Gastroenterol 2013;27(9):513-518.

BACKGROUND: In patients presenting with ascending cholangitis, better outcomes are reported in those undergoing endoscopic retrograde cholangiopancreatography (ERCP) compared with surgical drainage. OBJECTIVE: To identify factors associated with the type of intervention, and to examine temporal trends in the treatment of ascending cholangitis.

METHODS: Data were extracted from the Nationwide Inpatient Sample. Patients $\geq 18$ years of age with a diagnosis of cholangitis between 1998 and 2009 were selected. Temporal trends were assessed using Poisson regression models. Multivariable models were fitted to predict the likelihood of a patient undergoing ERCP, percutaneous or surgical drainage, or no drainage.

RESULTS: A weighted estimate of 248,942 patients admitted for cholangitis was identified. Overall, 131,052 patients were treated with ERCP (52.6\%), 10,486 with percutaneous drainage (4.2\%) and 12,460 with surgical drainage $(5.0 \%) ; 43.0 \%$ did not receive drainage during the admission. Temporal trends between 1998 and 2009 showed a decline in surgical and percutaneous drainage, and a rise in ERCP. In multivariable analyses adjusted for clustering, ERCP and percutaneous drainage were more often performed in institutions with a high volume of admissions for cholangitis, those with a greater bed number and hospitals located in urban areas.

CONCLUSION: Over the past decade, the use of surgical and percutaneous drainage has decreased while that of ERCP has risen. Patients treated at institutions with a low volume of admissions for cholangitis, small bed number and in rural areas were less likely to undergo ERCP or percutaneous drainage.
\end{abstract}

Key Words: Cholangitis; Endoscopic retrograde cholangiopancreatography (ERCP); Nationwide Inpatient Sample (NIS)

\section{La méthode de drainage biliaire et les tendances temporelles chez les patients hospitalisés en raison d'une cholangite : une vérification nationale}

HISTORIQUE : Chez les patients présentant une cholangite ascendante, ceux qui subissent une cholangiopancréatographie rétrograde endoscopique (CPRE) s'en sortent mieux que ceux qui subissent un drainage chirurgical. OBJECTIF : Déterminer les facteurs associés au type d'intervention et examiner les tendances temporelles dans le traitement de la cholangite ascendante.

MÉTHODOLOGIE : Les chercheurs ont extrait les données du Nationwide Inpatient Sample. Ils ont sélectionné les patients de 18 ans ou plus dont la cholangite avait été diagnostiquée entre 1998 and 2009. Ils ont évalué les tendances temporelles au moyen des modèles de régression de Poisson. Ils ont corrigé les modèles multivariables pour prédire la probabilité qu'un patient subisse une CPRE ou un drainage percutané ou chirurgical ou qu'il ne subisse pas de drainage.

RÉSULTATS : Les chercheurs ont recensé une estimation pondérée de 248942 patients hospitalisés en raison d'une cholangite. Dans l'ensemble, 131052 patients ont subi une CPRE (52,6\%), 10 486, un drainage percutané $(4,2 \%)$ et 12460 , un drainage chirurgical (5,0\%), tandis que 43,0\% n'ont pas subi de drainage pendant leur hospitalisation. Les tendances temporelles entre 1998 et 2009 ont révélé un fléchissement des drainages chirurgicaux et percutanés et une augmentation des CPRE. Selon les analyses multivariables corrigées pour tenir compte des regroupements, la CPRE et le drainage percutané étaient davantage exécutés dans les établissements présentant un fort volume d'hospitalisations en raison d'une cholangite, comptant un plus grand nombre de lits et situés en milieu urbain. CONCLUSION : Depuis dix ans, le recours au drainage chirurgical ou percutané a diminué tandis que les CPRE ont augmenté. Les patients étaient moins susceptibles de subir une CPRE ou un drainage percutané s'ils étaient traités dans des établissements situés en région rurale et comptant peu d'hospitalisations en raison d'une cholangite et peu de lits.

drainage approaches during an index admission. Our analysis relied on a large contemporary (1998 to 2009) population-based cohort of individuals admitted from the emergency department with ascending cholangitis.

antibiotherapy, as well as biliary drainage using an endoscopic, percutaneous or surgical approach (1). In 1992, a landmark randomized controlled trial by Lai et al (2) found that endoscopic retrograde cholangiopancreatography (ERCP) was associated with better outcomes than surgical decompression in patients presenting with severe ascending cholangitis. More recently, the Tokyo guidelines also favoured ERCP as the gold standard for biliary drainage in patients with cholangitis (3). They also categorized patients according to severity of presentation: mild, moderate and severe cholangitis. Mild cholangitis responds to antibiotherapy and supportive care and can be considered for elective biliary decompression.

Based on these considerations, we hypothesized that the use of ERCP for the treatment of acute cholangitis is on the rise and, accordingly, examined the temporal trends of biliary drainage for acute cholangitis. In addition, we aimed to identify predictors of the use of biliary

\section{METHODS}

Ethics

Institutional review board approval was not required because the present study did not involve the analysis of human subjects; a waiver was obtained from the University of Montreal Institutional Review Board (Montreal, Quebec). Because the present study involved the analysis of a population-based dataset, written consent by patients was not required.

\section{Data source}

Between 1998 and 2009, data from the Nationwide Inpatient Sample (NIS) were abstracted. The NIS includes inpatient discharge data

\footnotetext{
${ }^{1}$ Divison of Gastroenterology, McGill University, Montreal, Quebec; ${ }^{2}$ Department of Surgery, Henry Ford Health System, Detroit, Michigan, USA;

${ }^{3}$ Cancer Prognostics and Health Outcomes Unit, University of Montreal Health Centre, Montreal, Quebec

Correspondence: Dr Julia McNabb-Baltar, McGill University Health Centre, Montreal General Hospital site, 1650 Cedar Avenue, D7-346, Montreal,

Quebec H3G 1A4. Telephone 514-708-5857, fax 514-934-8375, e-mail julia.mcnabb-baltar@mail.mcgill.ca

Received for publication January 22, 2013. Accepted May 12, 2013
} 
collected via federal-state partnerships, as part of the Agency for Health care Research and Quality's Health care Cost and Utilization Project. As of 2009, the NIS contained administrative data on approximately eight million hospital stays each year from 1050 hospitals within 44 states - approximately $20 \%$ of community hospitals within the United States - including public hospitals and academic medical centres. The NIS is the sole hospital database in the United States with charge information on all patients regardless of payer, including persons covered by Medicare, Medicaid, private insurance and the uninsured.

\section{Sample population}

Using the International Classification of Diseases, Ninth Revision, Clinical Modification (ICD-9-CM), all patients ( $\geq 18$ years of age) with a diagnosis of cholangitis (ICD-9-CM code 576.1) admitted nonelectively from the emergency department were considered for the study, corresponding to a weighted national estimate of 248,942 cases.

\section{Baseline patient and hospital characteristics}

The following variables were available for all patients: age, sex, race (Caucasian, African American, Hispanic, Asian and Pacific Islander, Native American, other or missing), Charlson Comorbidity Index (CCI), day of admission (weekend, weekday), insurance status (private, Medicare, Medicaid, uninsured and other), socioeconomic status, annual hospital caseload, as well as hospital region, total bed size (small, medium, large), location and teaching status. Information regarding hospital region was obtained from the American Hospital Association Annual Survey of Hospitals, and defined by the United States Census Bureau (4). The CCI was derived from ICD-9 codes according to previously established criteria (5) and was stratified according to four levels: $0,1,2$ and $\geq 3$. Socioeconomic status was derived from median zip code income and was stratified according to quartiles: very low; low; high; and very high. Annual hospital caseload was defined according to the number of patients admitted with cholangitis at each participating institution during each study calendar year. Hospitals were divided into caseload quartiles, defined as $\leq 8,9$ to 15,16 to 27 and $\geq 28$. Hospitals were dichotomized into academic and nonacademic institutions. The hospital's academic status was obtained from the American Hospital Association Annual Survey of Hospitals. A hospital was considered to be a teaching hospital if it had an American Medical Association-approved residency program, was a member of the Council of Teaching Hospitals or had a ratio of fulltime equivalent interns and residents to beds $\geq 0.25$.

\section{Procedures performed during hospitalization}

Procedures, including diagnostic and therapeutic ERCP (ICD-9-CM codes 51.10, 51.11, 52.13, 51.14, 51.64, 51.81, 51.85, 51.86, 51.87, $51.88,51.99$ and 97.05$)$ and percutaneous transhepatic drainage with or without stone extraction (ICD-9-CM codes 51.98 and 51.96), surgical drainage (ICD-9-CM codes 51.41, 51.42, 51.43, 51.49, 51.51 and 51.59), were assessed. No procedure was defined as absence of ERCP, percutaneous and surgical drainage during the index admission.

\section{Etiology of the biliary obstruction}

The etiology of biliary obstruction was stratified as choledocholithiasis (ICD-9-CM code 574.x), neoplastic process (ie, cholangiocarcinoma, pancreatic cancer, gallbladder carcinoma, ampullary carcinoma and other) (ICD-9-CM codes 155.1, 156.0, 156.1, 156.2, 156.8, 156.9, 157.0, 157.1, 157.2, 157.3, 157.4, 157.8, 157.9, 230.8 and 235.3) and unknown or other etiology of obstruction (ICD-9-CM codes 576.2, 576.9 and 751.61).

\section{In-hospital mortality, length of stay and hospital charges}

In-hospital mortality information was coded from disposition of the patient. Length of stay (LOS), provided by the NIS, was calculated by subtracting the admission date from the discharge date. Prolonged LOS was defined as a hospital stay beyond the 75th percentile of 10 days. High hospital charges (HC) were defined as charges above the 75 th percentile of $\$ 46,740$. Patients with missing or invalid LOS, HC and in-hospital mortality status were not considered in the current study nor were patients transferred to another facility.

\section{Statistical analysis}

Descriptive statistics focused on frequencies and proportions for categorical variables. Means, medians and ranges were reported for continuously coded variables. One-way ANOVA and $\chi^{2}$ tests were used to assess the statistical significance of medians and proportions, respectively. Poisson regression models were used to evaluate the statistical significance of rate of utilization of ERCP, percutaneous, surgical and no drainage over time. Because the data are nationally representative, using year of admission as a continuous variable in Poisson model equates to a trend test that accounts for the variability of the volume estimate (6).

Multivariable logistic regression models were used to adjust for confounding. Four models were created using, in turn, the use of ERCP, percutaneous drainage and surgical drainage, as well as the absence of a decompression procedure during the index admission as dependent variables, while adjusting for the effect of patient and hospital characteristics including hospitals with high volumes of admissions for cholangitis. Within each model, generalized estimating equations adjusted for clustering within hospitals. All tests were two-sided with statistical significance set at $\mathrm{P}=0.001$. Analyses were conducted using the $\mathrm{R}$ statistical package version 2.15.0 ( $\mathrm{R}$ foundation for Statistical Computing, USA).

\section{RESULTS}

\section{Study sample, demographics and clinical characteristics}

Overall, a weighted estimate of 248,942 patients admitted with cholangitis was identified. During the index admission, 106,933 patients did not require drainage $(43.0 \%), 131,052$ were treated with ERCP $(52.6 \%), 10,486$ with percutaneous drainage $(4.2 \%)$ and $12,460(5.0 \%)$ with surgical drainage (percentages not mutually exclusive). The median age of the patients was 70 years; $49.6 \%$ were men. Regarding comorbidities, $6.0 \%$ of patients had a CCI score of 0 , while $90.6 \%$ had a CCI score $\geq 3$. The majority $(54.8 \%)$ of patients were Caucasian, $10.2 \%$ were Hispanic, $6.6 \%$ were African American, and $5.1 \%$ were Asian and Pacific Islander. They were mostly admitted during weekdays (72.3\%). According to etiology of obstruction, $46.2 \%$ of patients had choledocholithiasis, $10.5 \%$ had malignant obstruction, and $43.4 \%$ had an unknown or other etiology of obstruction. A more detailed breakdown of demographics stratified according to treatment type is shown in Table 1.

\section{Trends in procedure use}

Temporal trends of procedure use between 1998 and 2009 showed a significant decline in surgical drainage (from $8.2 \%$ to $2.8 \% ; \mathrm{P}<0.001$ ), and more modest decreases in both percutaneous drainage $(5.0 \%$ to $4.6 \% ; \mathrm{P}<0.001)$ and no drainage during the index admission $(40.0 \%$ to $39.5 \% ; \mathrm{P}<0.001)$. Conversely, a rise in ERCP use was observed over the same period (from $54.2 \%$ to $57.0 \% ; \mathrm{P}<0.001$ ). Figure 1 illustrates the complete temporal trends in procedure use.

\section{Multivariable analyses}

In multivariable analyses adjusting for clustering, no drainage procedure during the index admission was more likely in African Americans and neoplastic obstruction. Conversely, it was less likely in patients with advanced age, Hispanic, Asian and Pacific Islander background, patients with CCI score $\geq 3$, and in hospitals with more admissions for cholangitis, greater bed number, in urban settings and with a teaching academic status. The use of ERCP was more common in older patients, Hispanics and those with CCI score $\geq 3$ treated in hospitals with higher cholangitis caseload, greater bed number, in urban settings and with teaching status. ERCP was less likely to be used in African American patients with neoplastic obstruction. Percutaneous drainage was more often performed in patients of older age, CCI score $\geq 3$, malignant obstruction and in hospitals with more admissions 
TABLE 1

Demographic characteristics of a weighted number of patients admitted with cholangitis, stratified according to procedure performed during admission (Nationwide Inpatient Sample, 1998 to 2009)

\begin{tabular}{|c|c|c|c|c|c|}
\hline & $\begin{array}{c}\text { All } \\
\text { patients }\end{array}$ & $\begin{array}{l}\text { No pro- } \\
\text { cedure }\end{array}$ & ERCP & $\begin{array}{c}\text { Percutaneous } \\
\text { drainage }\end{array}$ & $\begin{array}{l}\text { Surgical } \\
\text { drainage }\end{array}$ \\
\hline Patients, $\mathrm{n}$ & 248,942 & 106,933 & 131,052 & 10,486 & 12,460 \\
\hline $\begin{array}{l}\text { Median age, years } \\
\text { (25th, 75th } \\
\text { percentile [IQR]) }\end{array}$ & $\begin{array}{l}70(55, \\
80[25])\end{array}$ & $\begin{array}{l}67(51, \\
79 \text { [28]) }\end{array}$ & $\begin{array}{l}72(57, \\
81[24])\end{array}$ & $\begin{array}{c}69(56,79 \\
[23])\end{array}$ & $\begin{array}{l}74(61, \\
82[21])\end{array}$ \\
\hline \multicolumn{6}{|l|}{ Sex } \\
\hline Male & 49.6 & 50.3 & 48.8 & 51.9 & 48.2 \\
\hline Female & 50.4 & 49.7 & 51.2 & 48.1 & 51.8 \\
\hline \multicolumn{6}{|l|}{$\mathrm{CCl}^{*}$} \\
\hline 0 & 6.0 & 10.1 & 2.9 & 4.3 & 0.9 \\
\hline 1 & 2.7 & 4.5 & 1.3 & 1.5 & 0.3 \\
\hline 2 & 0.7 & 1.1 & 0.4 & 0.6 & 0.1 \\
\hline$\geq 3$ & 90.6 & 84.4 & 95.4 & 93.6 & 98.8 \\
\hline \multicolumn{6}{|l|}{ Race } \\
\hline Caucasian & 54.8 & 54.4 & 55.2 & 53.2 & 52.6 \\
\hline African American & 6.6 & 7.6 & 5.7 & 8.2 & 5.2 \\
\hline Hispanic & 10.2 & 8.7 & 11.5 & 10.3 & 11.5 \\
\hline $\begin{array}{l}\text { Asians and } \\
\text { Pacific Islanders }\end{array}$ & 5.1 & 4.0 & 5.8 & 7.1 & 7.4 \\
\hline Native American & 0.3 & 0.3 & 0.3 & 0.1 & 0.1 \\
\hline Other & 2.0 & 1.6 & 2.3 & 2.2 & 2.7 \\
\hline Unknown & 21.1 & 23.3 & 19.3 & 18.9 & 20.5 \\
\hline \multicolumn{6}{|l|}{ Socioeconomic status } \\
\hline Very low & 16.0 & 17.1 & 15.2 & 15.9 & 15.1 \\
\hline Low & 22.8 & 24.0 & 21.7 & 18.6 & 25.6 \\
\hline High & 25.4 & 25.1 & 25.8 & 24.5 & 26.3 \\
\hline Very high & 33.4 & 31.2 & 35.0 & 38.7 & 30.9 \\
\hline Unknown & 2.4 & 2.5 & 2.4 & 2.2 & 2.1 \\
\hline \multicolumn{6}{|l|}{ Day of admission } \\
\hline Weekday & 72.3 & 72.3 & 72.2 & 73.4 & 72.4 \\
\hline Weekend & 27.5 & 27.5 & 27.5 & 26.2 & 27.3 \\
\hline Unknown & 0.2 & 0.2 & 0.2 & 0.3 & 0.2 \\
\hline \multicolumn{6}{|l|}{ Insurance } \\
\hline Private & 27.1 & 30.1 & 24.8 & 29.1 & 20.2 \\
\hline Medicaid & 8.6 & 8.9 & 8.4 & 9.1 & 8.9 \\
\hline Medicare & 57.9 & 54.8 & 60.3 & 56.1 & 63.3 \\
\hline Other & 6.3 & 6.2 & 6.5 & 5.8 & 7.5 \\
\hline \multicolumn{6}{|l|}{ Diagnosis } \\
\hline Choledocholithiasis & 46.2 & 25.1 & 63.1 & 25.5 & 84.8 \\
\hline Neoplasm & 10.5 & 8.8 & 11.2 & 30.2 & 4.8 \\
\hline Unknown & 43.4 & 66.1 & 25.7 & 44.2 & 10.4 \\
\hline \multicolumn{6}{|c|}{ Annual hospital caseload } \\
\hline 1st quartile & 28.0 & 35.2 & 21.9 & 14.0 & 37.7 \\
\hline 2nd quartile & 23.7 & 22.4 & 25.1 & 19.1 & 26.0 \\
\hline 3rd quartile & 24.7 & 22.1 & 26.9 & 28.4 & 22.7 \\
\hline 4th quartile & 23.6 & 20.3 & 26.1 & 38.5 & 13.6 \\
\hline \multicolumn{6}{|l|}{ Hospital location } \\
\hline Rural & 12.2 & 18.0 & 7.3 & 3.3 & 16.1 \\
\hline Urban & 87.8 & 82.0 & 92.7 & 96.7 & 83.9 \\
\hline \multicolumn{6}{|c|}{ Hospital region (United States) ${ }^{\dagger}$} \\
\hline Northeast & 22.6 & 22.6 & 25.1 & 26.7 & 20.5 \\
\hline Midwest & 19.0 & 19.3 & 16.7 & 13.3 & 16.8 \\
\hline South & 31.7 & 31.5 & 29.8 & 32.3 & 34.0 \\
\hline West & 26.8 & 26.6 & 28.2 & 27.7 & 28.7 \\
\hline
\end{tabular}

TABLE 1 - CONTINUED

Demographic characteristics of a weighted number of patients admitted with cholangitis, stratified according to procedure performed during admission (Nationwide Inpatient Sample, 1998 to 2009)

\begin{tabular}{|c|c|c|c|c|c|}
\hline & $\begin{array}{c}\text { All } \\
\text { patients }\end{array}$ & $\begin{array}{l}\text { No pro- } \\
\text { cedure }\end{array}$ & ERCP & $\begin{array}{c}\text { Percutaneous } \\
\text { drainage }\end{array}$ & $\begin{array}{l}\text { Surgical } \\
\text { drainage }\end{array}$ \\
\hline \multicolumn{6}{|c|}{ Bed size of hospital } \\
\hline Small & 10.9 & 12.5 & 9.6 & 7.0 & 11.5 \\
\hline Medium & 25.8 & 26.9 & 25.0 & 20.4 & 28.5 \\
\hline Large & 63.3 & 60.5 & 65.4 & 72.6 & 60.0 \\
\hline \multicolumn{6}{|c|}{ Institutional academic status } \\
\hline Nonteaching & 56.5 & 57.2 & 50.5 & 34.5 & 61.7 \\
\hline Teaching & 43.5 & 42.8 & 49.5 & 65.5 & 38.3 \\
\hline
\end{tabular}

Data presented as \% unless otherwise indicated. *Charlson Comorbidity Index (CCI) status based on comorbidity developed by Charlson et al and adapted by Deyo et al (5); ${ }^{\dagger}$ Hospital region defined by the United States Census Bureau. ERCP Endoscopic retrograde cholangiopancreatography; IQR Interquartile range

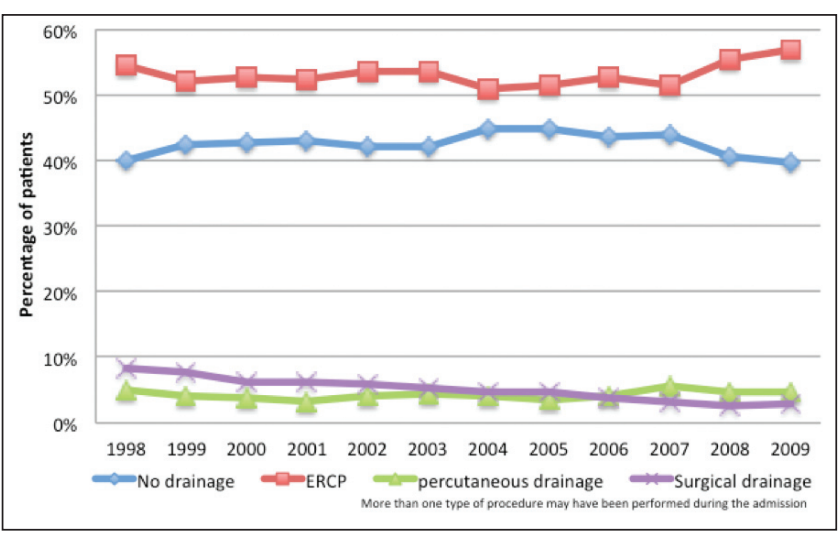

Figure 1) Temporal trends in procedure use for acute ascending cholangitis, Nationwide Inpatient Sample, 1998 to 2009. ERCP Endoscopic retrograde cholangiopancreatography

for cholangitis, hospital beds, in urban and teaching settings. Finally, surgical drainage was more likely in older, Asian and Pacific Islander, $\mathrm{CCI} \geq 3$ patients. It was performed less often in malignant obstructions and in hospitals with high cholangitis caseload. A list of all corresponding ORs and statistical significance is shown in Table 2.

In-hospital mortality, high $\mathrm{HC}$ and prolonged LOS

Mortality was $7.6 \%$ in the no procedure, $3.3 \%$ in the ERCP, $8.9 \%$ in the percutaneous drainage and $7.1 \%$ in the surgical drainage groups. There were fewer patients with a prolonged LOS ( $>10$ days) in those undergoing no drainage or ERCP during the index admission (18.1\% and $26.8 \%$ versus $55.5 \%$ and $55.6 \%$, respectively); similar findings were noted for high $\mathrm{HC}(>\$ 46,740)(20.0 \%$ and $32.7 \%$ versus $54.7 \%$ and $51.0 \%)$. Associations are more completely shown in Table 3.

\section{DISCUSSION}

The treatment of ascending cholangitis has evolved considerably over the past few decades. With the improvement in biliary drainage techniques, mortality in cholangitis has declined (7). In the present study, we explored factors associated with the use of different biliary drainage modalities as treatment for cholangitis, as well as utilization trends over a decade.

Several of our findings are noteworthy. First, our results demonstrate an important variation in outcomes according to the biliary drainage treatment received by patients. Specifically, the rates of inhospital mortality, HC and LOS were lower in the ERCP group, relative to the surgical and percutaneous drainage groups. Although patient selection may have contributed, we attempted to adjust for 
TABLE 2

Multivariable logistic regression analyses with general estimation equation adjustment assessing biliary drainage procedure during admission (Nationwide Inpatient Sample, 1998 to 2009)

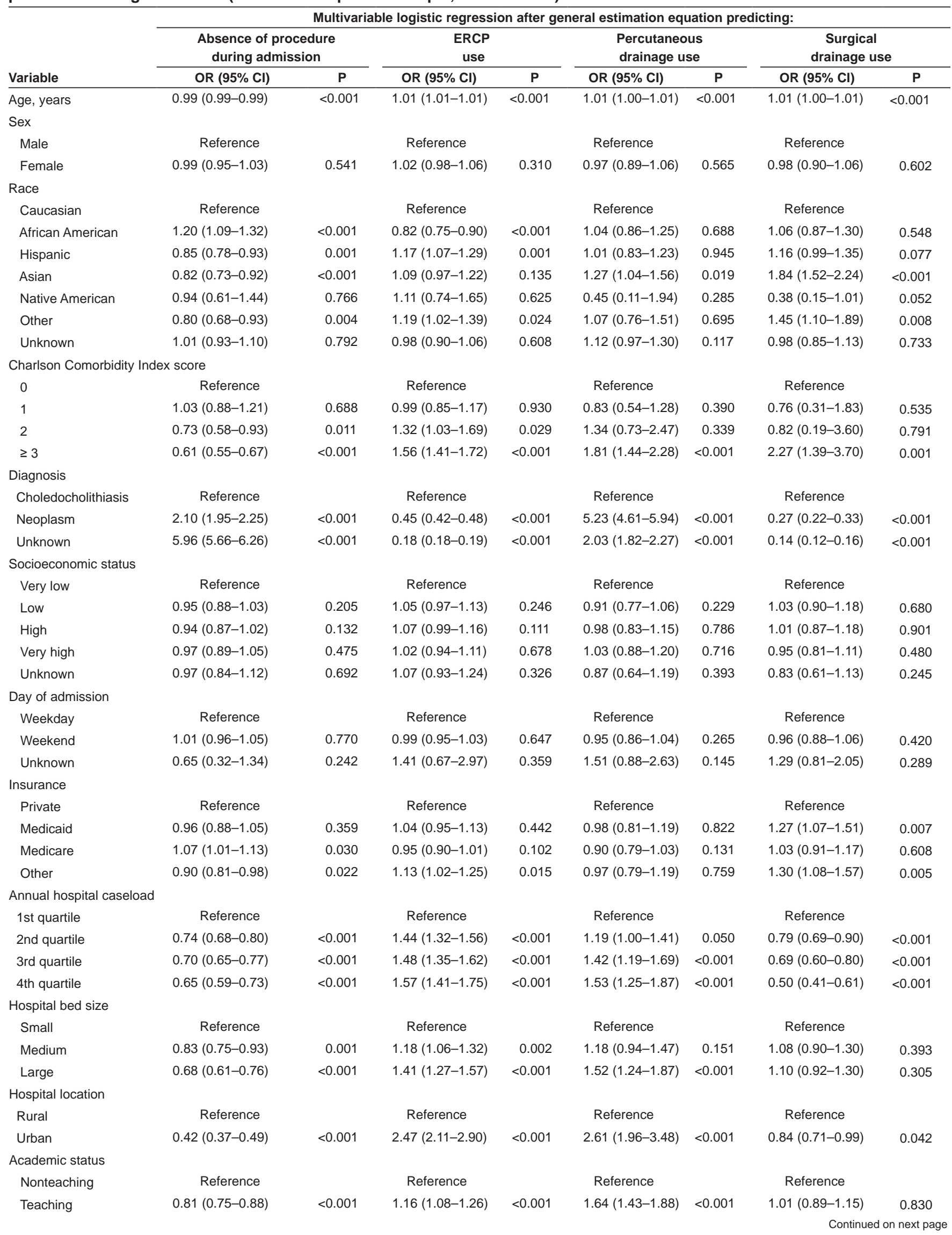


TABLE 2 - CONTINUED

Multivariable logistic regression analyses with general estimation equation adjustment assessing biliary drainage procedure during admission (Nationwide Inpatient Sample, 1998 to 2009)

\begin{tabular}{|c|c|c|c|c|c|c|c|c|}
\hline \multirow[b]{3}{*}{ Variable } & \multicolumn{8}{|c|}{ Multivariable logistic regression after general estimation equation predicting: } \\
\hline & \multicolumn{2}{|c|}{$\begin{array}{l}\text { Absence of procedure } \\
\text { during admission }\end{array}$} & \multicolumn{2}{|l|}{$\begin{array}{c}\text { ERCP } \\
\text { use }\end{array}$} & \multicolumn{2}{|c|}{$\begin{array}{l}\text { Percutaneous } \\
\text { drainage use }\end{array}$} & \multicolumn{2}{|c|}{ Surgical drainage use } \\
\hline & OR $(95 \% \mathrm{Cl})$ & $\mathbf{P}$ & OR $(95 \% \mathrm{Cl})$ & $\mathbf{P}$ & OR $(95 \% \mathrm{Cl})$ & $\mathbf{P}$ & OR $(95 \% \mathrm{Cl})$ & $\mathbf{P}$ \\
\hline \multicolumn{9}{|c|}{ Hospital region (United States) } \\
\hline Northeast & Reference & & Reference & & Reference & & Reference & \\
\hline Midwest & $1.11(1.00-1.24)$ & 0.053 & $0.92(0.82-1.03)$ & 0.147 & $0.76(0.60-0.94)$ & 0.014 & $1.01(0.83-1.21)$ & 0.948 \\
\hline South & $0.98(0.89-1.08)$ & 0.672 & $0.99(0.89-1.09)$ & 0.762 & $1.28(1.06-1.53)$ & 0.009 & $1.12(0.95-1.31)$ & 0.181 \\
\hline West & $1.11(1.01-1.22)$ & 0.029 & $0.88(0.80-0.97)$ & 0.011 & $0.96(0.78-1.18)$ & 0.685 & $1.12(0.95-1.33)$ & 0.187 \\
\hline
\end{tabular}

patient and institutional factors; furthermore, this finding was previously reported in the randomized controlled trial by Lai et al (2), which supported ERCP as the gold standard for biliary drainage in cholangitis. It is also noteworthy that $43.0 \%$ of patients did not undergo drainage during the index procedure. Some of these patients likely represent cases of mild cholangitis who were eventually treated with elective outpatient decompression (8), which is not recorded in the NIS. This hypothesis would account for the lower rates of $\mathrm{HC}$ and LOS noted in this group. Alternatively, it is also possible that the remaining patients in the group were sicker at presentation or did not receive appropriate drainage (9), explaining the higher rate of mortality relative to the ERCP group.

Second, we show that the use of endoscopic drainage, as a treatment for cholangitis, has been rising in the past decade. During the same period, there was a steep fall in the use of surgical biliary drainage, and a modest decrease in the use of percutaneous and no drainage during the index admission. These observations are expected, given the findings of the Lai trial (2) and other series from the same years (10-12). Although the temporal trends of ERCP utilization have been described in the past (13), to our knowledge, the current study represents the first analysis of temporal trends of biliary drainage approaches in the context of acute cholangitis.

Third, we identified hospital characteristics associated with the use of different biliary decompression methods. We found that patients admitted to hospitals with high volumes of admission for cholangitis and/or located in urban settings were less likely to undergo surgical drainage and more likely to undergo ERCP and percutaneous drainage. Similarly, large hospital and teaching hospitals were more likely to perform endoscopic or percutaneous biliary drainage. These findings may be due to a referral bias, in which more complex cases are selectively referred to centres of excellence where state-of-the-art treatments are available. It is also possible that the lack of endoscopic and percutaneous expertise in some areas could have prevented these procedures from being performed. In fact, within the current study, increasing hospital caseload portended a higher likelihood of undergoing ERCP and percutaneous drainage. Conversely, patients admitted to small hospitals with low volume of admission for cholangitis in rural, nonteaching settings were less likely to receive biliary drainage during the index admission. This could be explained by a combination of factors. These patients may be younger, healthier, exhibit a less severe presentation and are able to safely receive elective biliary drainage. Alternatively, as discussed above, some of them may also have been too sick to receive timely treatment or require transfer in a more specialized centre.

Certain patient characteristics were also associated with specific trends in procedure use. Older age and CCI score were associated with biliary drainage during the admission. As such, we corroborate previous reports that older patients and patients with more comorbidities are likely to be sicker at presentation and to require drainage urgently $(14,15)$. Moreover, patients with neoplastic obstruction were more likely to receive no drainage or percutaneous drainage, but less likely to receive endoscopic or surgical drainage than patients with stone disease. In fact, previous investigations have shown that percutaneous
TABLE 3

In-hospital mortality, high hospital charges and prolonged length of stay according to procedure performed

\begin{tabular}{lcccc}
\hline & No procedure & ERCP & $\begin{array}{c}\text { Percutaneous } \\
\text { drainage }\end{array}$ & $\begin{array}{c}\text { Surgical } \\
\text { drainage }\end{array}$ \\
\hline $\begin{array}{l}\text { Weighted number } \\
\text { of patients, } \mathrm{n}\end{array}$ & 106,933 & 131,052 & 10,486 & 12,460 \\
$\begin{array}{l}\text { Mortality } \\
\begin{array}{l}\text { High hospital } \\
\text { charges }\end{array}\end{array}$ & 7.6 & 3.3 & 8.9 & 7.1 \\
$\begin{array}{l}\text { Prolonged length of } \\
\text { stay }\end{array}$ & 18.1 & 32.7 & 54.7 & 51.0 \\
\hline
\end{tabular}

Data presented as \% unless otherwise indicated. ERCP Endoscopic retrograde cholangiopancreatography

drainage is more often required in more proximal biliary obstruction (16). With regard to race, African Americans were more likely to receive no drainage, while Hispanics, Asians and Pacific Islanders were more likely to undergo biliary drainage during the index admission. Furthermore, more Hispanic - but fewer African American - patients were treated with ERCP compared with Caucasians. Increased ERCP use in Hispanics has already been described (13) and is possibly related to the increased prevalence of biliary stones in that population (17). Asian and Pacific Islander patients were at increased odds of undergoing surgical drainage relative to Caucasian patients. This may be due to increased prevalence of biliary tract pathologies, such as hepatolithiasis and choledochal cysts (18), which often require surgical management (19). Collectively, it is worrisome that despite the decreased risk of periprocedural morbidity of ERCP (2), some patients may be denied such benefits although residual confounding may hamper such interpretation. Specifically, some patients may be denied ERCP based on individual baseline characteristics and sociodemographic variables, as well as the hospital at which they are treated. Collectively, these trends raise questions about possible differential treatment paradigms for cholangitis among centres of excellence and the community. Moreover, they serve as an indication that disparities in treatment remain in routine clinical practice, even in contemporary years. Efforts should be made to more specifically address the causes of these findings and reduce such discrepancies.

Despite its strengths, our study was not devoid of limitations. Limitations include the study design; in fact, observational studies cannot be used as proof of a causal relationship. Some reasons for this are the inability to adjust for important patient variables such as disease characteristics, personal preferences, education and disease severity. Unavailability of individual gastroenterologist, surgeon and interventional radiologist volume data represents an additional limitation, which is shared by several other analyses $(20,21)$. It is also possible that the true mortality was underestimated because some patients may have died at other institutions where their mortality was not captured. Furthermore, the accuracy of administrative ICD-9-CM claims data for identification of cholangitis and ERCP has never 
been validated within the NIS, which could lead to some degree of misclassification. Finally, follow-up data on patients not receiving biliary drainage were not available within the NIS and would have been useful to better assess the degree of acuity and the outcomes of this group of patients.

\section{CONCLUSION}

The majority of patients admitted with cholangitis underwent endoscopic drainage, while $43.0 \%$ did not undergo any biliary drainage procedure during the index hospitalization. The use of surgical and percutaneous drainage as a treatment for ascending cholangitis has decreased while that of ERCP has risen over the past decade. Patients treated at institutions with a low volume of admissions for cholangitis, small bed number and in rural settings were less likely to undergo ERCP or percutaneous drainage. Access to ERCP in such settings needs to be more closely evaluated and may need to be improved.

\section{REFERENCES}

1. Boey JH, Way LW. Acute cholangitis. Ann Surg 1980;191:264-70.

2. Lai EC, Mok FP, Tan ES, et al. Endoscopic biliary drainage for severe acute cholangitis. N Engl J Med 1992;326:1582-6.

3. Mayumi T, Takada T, Kawarada Y, et al. Results of the Tokyo Consensus Meeting Tokyo Guidelines. J Hepatobiliary Pancreat Surg 2007;14:114-21.

4. United States Census Bureau. 2000 [cited 2011] <www.census.gov> (Accessed December 2011).

5. Deyo RA, Cherkin DC, Ciol MA. Adapting a clinical comorbidity index for use with ICD-9-CM administrative databases. J Clin Epidemiol 1992;45:613-9.

6. Selvin S. Statistical Analysis of Epidemiologic Data. New York: Oxford University Press Inc; 2004:228.

7. Jamal MM, Yamini D, Singson Z, et al. Decreasing hospitalization and in-hospital mortality related to cholangitis in the United States. J Clin Gastroenterol 2011;45:e92-6.

8. Williams EJ, Green J, Beckingham I, et al. Guidelines on the management of common bile duct stones (CBDS). Gut 2008;57:1004-21.
9. Ren Z, Xu Y, Zhu S. Percutaneous transhepatic cholecystostomy for choledocholithiasis with acute cholangitis in high-risk patients. Hepatogastroenterology 2011;59.

10. Tandon RK, Saraswat VA, Kapur BM, et al. Duodenoscopic sphincterotomy for acute suppurative cholangitis. J Gastroenterol Hepatol 1989;4:33-40.

11. Saraswat VA, Kapur BM, Vashisht S, et al. Duodenoscopic sphincterotomy for common bile duct stones in patients with gallbladder in situ. Int Surg 1991;76:142-5.

12. Graham SM, Flowers JL, Scott TR, et al. Laparoscopic cholecystectomy and common bile duct stones. The utility of planned perioperative endoscopic retrograde cholangiography and sphincterotomy: Experience with 63 patients. Ann Surg 1993;218:61-7.

13. Mazen Jamal M, Yoon EJ, Saadi A, et al. Trends in the utilization of endoscopic retrograde cholangiopancreatography (ERCP) in the United States. Am J Gastroenterol 2007;102:966-75.

14. Ouellette JR, Small DG, Termuhlen PM. Evaluation of CharlsonAge Comorbidity Index as predictor of morbidity and mortality in patients with colorectal carcinoma. J Gastrointest Surg 2004;8:1061-7.

15. Janssen-Heijnen ML, Maas HA, Houterman S, et al. Comorbidity in older surgical cancer patients: Influence on patient care and outcome. Eur J Cancer 2007;43:2179-93.

16. Covey AM, Brown KT. Palliative percutaneous drainage in malignant biliary obstruction. Part 2: Mechanisms and postprocedure management. J Support Oncol 2006;4:329-35.

17. Maurer KR, Everhart JE, Ezzati TM, et al. Prevalence of gallstone disease in Hispanic populations in the United States. Gastroenterology 1989;96:487-92.

18. Lipsett PA, Pitt HA, Colombani PM, et al. Choledochal cyst disease. A changing pattern of presentation. Ann Surg 1994;220:644-52.

19. Kim MH, Sekijima J, Lee SP. Primary intrahepatic stones. Am J Gastroenterol 1995;90:540-8.

20. Hoh BL, Chi YY, Waters MF, et al. Effect of weekend compared with weekday stroke admission on thrombolytic use, in-hospital mortality, discharge disposition, hospital charges, and length of stay in the Nationwide Inpatient Sample Database, 2002 to 2007. Stroke 2010;41:2323-8.

21. Kelz RR, Gimotty PA, Polsky D, et al. Morbidity and mortality of colorectal carcinoma surgery differs by insurance status. Cancer 2004;101:2187-94. 


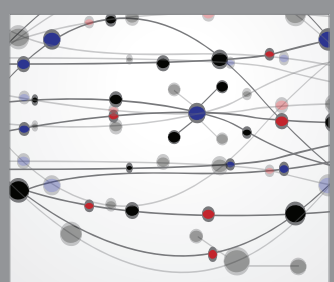

The Scientific World Journal
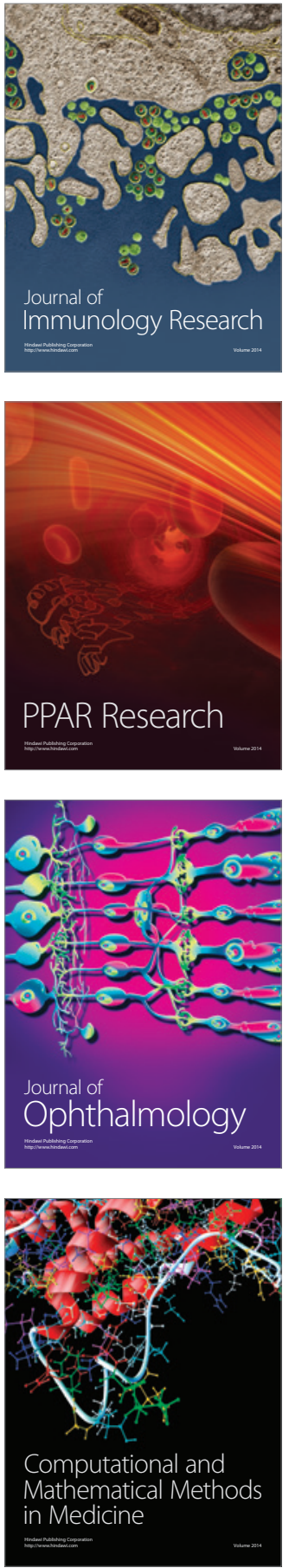

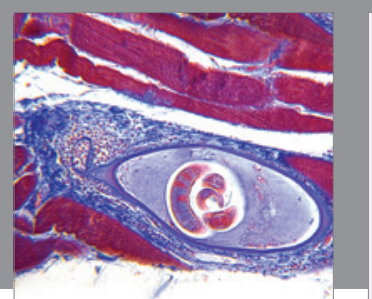

Gastroenterology Research and Practice

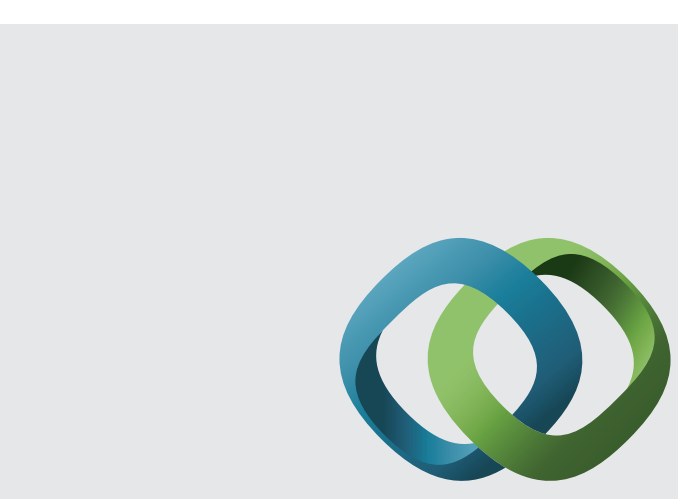

\section{Hindawi}

Submit your manuscripts at

http://www.hindawi.com
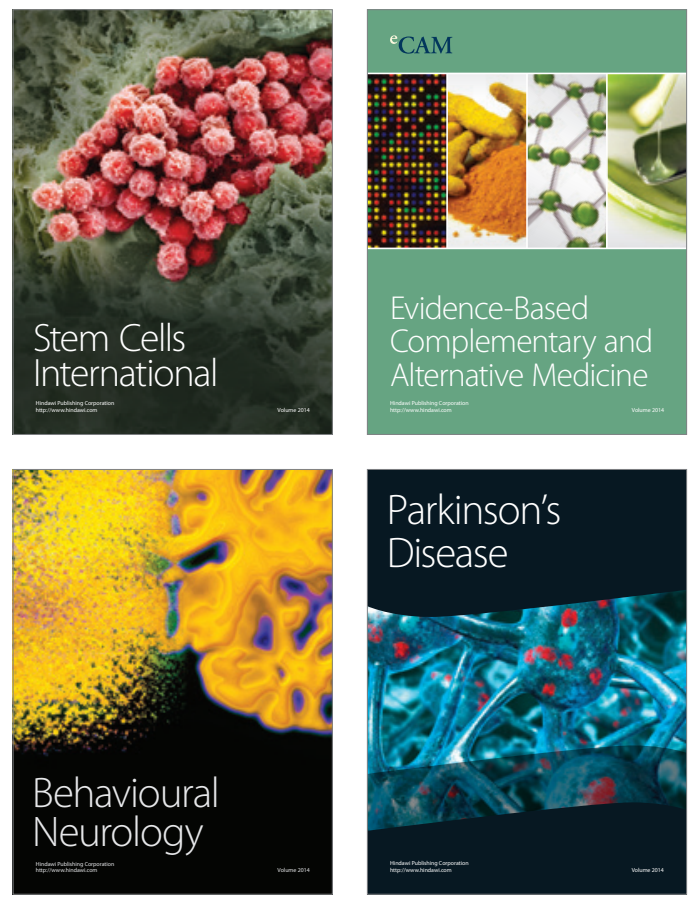
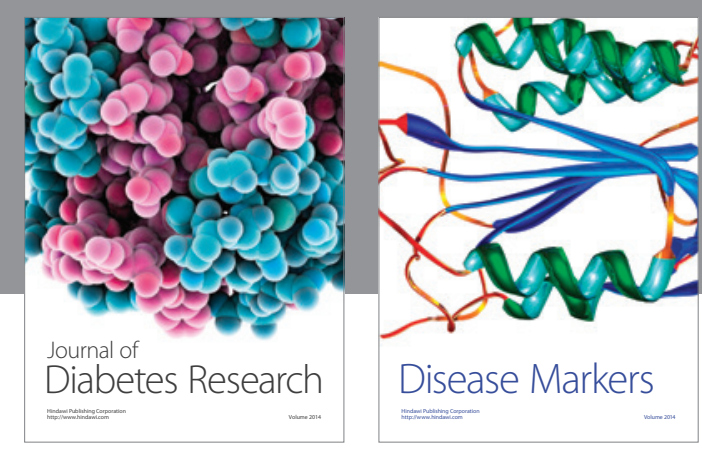

Disease Markers
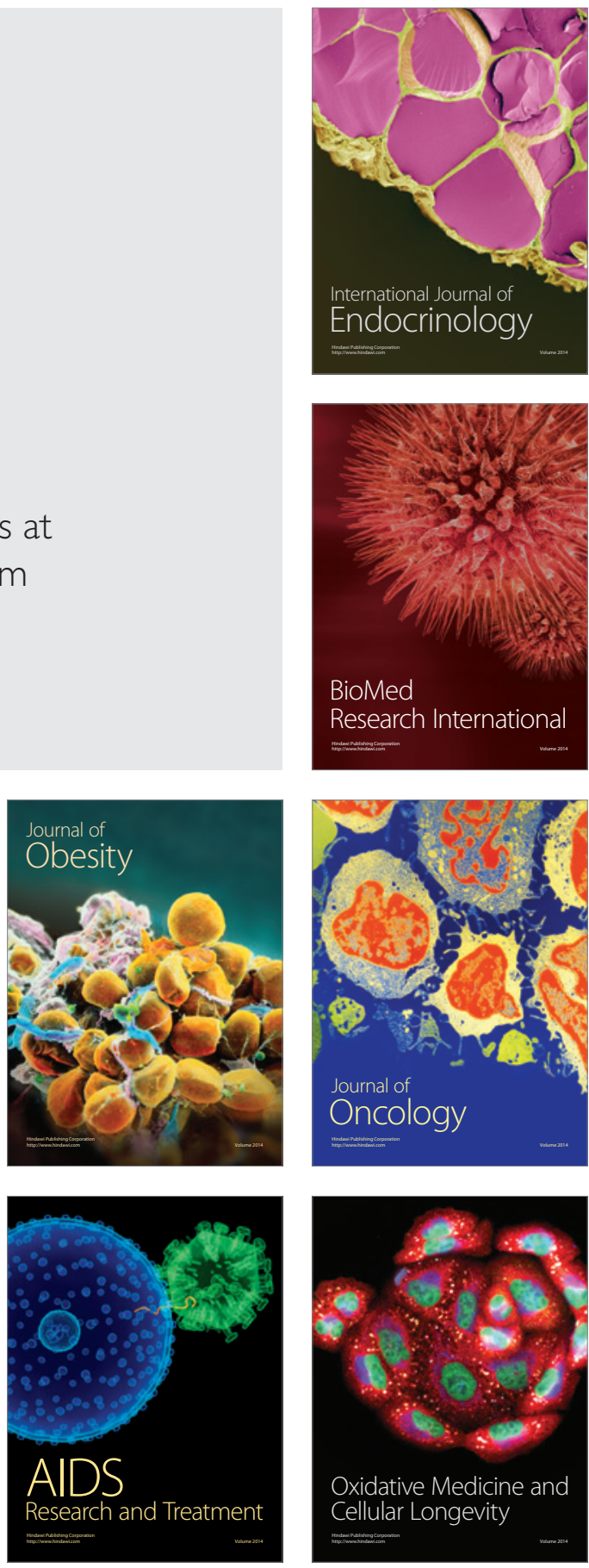